\title{
Stiff Leg Syndrome and Myelitis with Anti-Amphiphysin Antibodies: A Common Physiopathology?
}

\author{
Ludivine Chamard $^{\mathrm{a}}$ Eloi Magnin ${ }^{\mathrm{a}}$ Eric Berger ${ }^{\mathrm{a}}$ Beate Hagenkötter ${ }^{\mathrm{c}}$ Lucien Rumbach $^{\mathrm{a}} \mathrm{b}$ \\ Marc Bataillard ${ }^{c}$ \\ a Department of Neurology, and ${ }^{b}$ Centre d'investigation clinique en innovation technologique (Inserm CIT 808), \\ University Hospital of Besançon, Besançon, and ${ }^{\mathrm{C}}$ Department of Neurology, Belfort-Montbéliard Hospital, \\ Belfort-Montbéliard, France
}

Dear Sir,

Stiff man syndrome is a rare neurological pathology first described in 1956 by Moersch and Woltman [1]. Four forms of the illness have been identified: stiff person syndrome, which is characterized by contractions and axial muscle rigidity; progressive encephalomyelitis with rigidity, characterized by diffuse rigidity and cognitive disorders; jerking stiff man syndrome, characterized by limb myoclonus and respiratory disorders; and stiff leg syndrome (SLS), which is characterized by focal rigidity and is different in various ways [2]. Anti-GAD antibodies are positive in only $15 \%$ of cases of SLS. Contractions and rigidity affect only one or two limbs. A paraneoplastic etiology is rarely associated with it. Medullary and cerebral MRI do not usually show any abnormalities [3].

We report the case of a patient suffering from SLS with anti-amphiphysin antibodies revealing breast cancer, with paraneoplastic transverse myelitis (TM) images appearing later in MRI with no associated neurological deficit.

\section{Case Report}

Mrs. H., aged 65, presented to the Neurology Department in July 2009 with painful stiffness in the lower limbs and diffi- culty in walking. The symptoms had first appeared 2 weeks earlier. Her medical history included type 2 diabetes treated with metformin and a thyroid goiter treated with surgery and levothyroxine.

On clinical examination, she presented permanent hypertonia in the lower limb and bilateral dystonia of the extensor hallucis longus muscles. Intermittent spasms were associated with hypertonia. The spasms lasted several seconds and were spontaneous, painful, and made worse by anxiety and cutaneous stimulation. The tibialis anterior muscles were hypertrophied.

Electroneuromyography (ENMG) carried out under diazepam was normal. Cerebral and medullary MRI (fig. 1) were normal. A PET scan showed an anomaly on the right breast. A mammography, breast ultrasound and biopsy confirmed the diagnosis of infiltrating canal carcinoma of the breast.

The standard biological assessment was normal. Cerebrospinal fluid (CSF) tests showed pleocytosis (14 white blood cells), a high protein level ( $0.81 \mathrm{~g} / \mathrm{l})$ and intrathecal IgG synthesis with monoclonal bands. Other biological examinations were done: Lyme disease, HTLV (1 and 2) and tetanus serology were negative. Tests for antiphospholipid, antinuclear and anti-GAD antibodies were negative. No anti- neural antibodies (Hu, Yo, $\mathrm{Ri}, \mathrm{CV} 2, \mathrm{Ma} 1$, Ma2) were found, but anti-amphiphysin antibodies were found in blood and CSF (qualitative measurement).

Intravenous corticotherapy ( $1 \mathrm{~g} /$ day for 5 days), associated with diazepam (5 $\mathrm{mg} 3$ times per day) and baclofene (10 $\mathrm{mg} 3$ times per day), was introduced. Spasms receded after 3 days, and the patient was able to walk again.

Evolution was marked by frequent relapses with profuse sweating without hyperthermia, treated by corticotherapy, diazepam and baclofene. Another ENMG showed simultaneous activity in the agonist and antagonist muscles and continuous activity in anterior tibialis muscles with intermittent spasms triggered after cutaneous stimulation.

Spasms in the legs exacerbated by emotion and cutaneous stimulation, hypertonia of the lower limbs, adrenergic signs, ENMG data, amphiphysin antibodies and pharmacosensitivity led to a diagnosis of SLS. Cancer was treated by surgery, radiotherapy and chemotherapy. Symptoms improved with the introduction of chemotherapy. After the fifth round, SLS worsened with no associated neurological deficit (pyramidal, sensitive or sphincteric).

Six months after disease onset, the patient complained of leg pain; therefore, an-

\section{KARGER}

Fax +4161306 1234 E-Mail karger@karger.ch www.karger.com www.karger.com/ene
Eloi Magnin

Department of Neurology

University Hospital of Besançon

FR-25000 Besançon (France)

Tel. +33 38166 8098, E-Mail eloi.magnin@laposte.net 
other medullary MRI was carried out, which showed an unexpected TM with a T2 hypersignal from level Th6 to Th10 (fig. 1). Anti-NMO antibodies were negative. As there was no worsening of SLS and no associated neurological deficit, TM was considered as an incidental finding and no specific treatment was administrated.

One year after disease onset, the patient could walk with two sticks and no longer presented with spasms; however, she still suffered from stiff lower limbs with no pyramidal syndrome. Her only treatment was tizanidine. No further medullar abnormalities were found in the medullary MRI carried out 3 months later.

\section{Discussion}

Our patient had two paraneoplastic neurological presentations caused by antiamphiphysin antibodies: firstly SLS, and secondly by extensive TM in imaging. The only sign of TM was nonspecific leg pain with no sign of associated medullary suffering and no worsening of SLS. To our knowledge, this is the first case of SLS and $\mathrm{TM}$ to be described in the literature. We suggest that a common medullary physiopathology may occur in these two pathologies.

The literature [3-19], including this case report, provides details of 31 patients: 23 women and 8 men (sex ratio: 1/3), with an average age of 49 (28-71), suffering from SLS. The search for anti-GAD antibodies was positive in 13 patients (42\%). However, the search for anti-amphiphysin antibodies was carried out in only 10 patients and was positive in only 2. Our patient was the only one to have pleocytosis. In 1 of 27 patients, medullary MRI showed a dispersed T2 hypersignal [3]. Our patient was the only one to undergo another MRI showing extensive TM 6 months after symptom onset. Virani et al. [20] reported a case of extensive paraneoplastic TM with anti-amphiphysin antibodies in breast cancer with stiffness and spasms, as well as sensory disorders. Holmøy et al. [21] described a case of SLS with an anatomopathological analysis of the spinal cord showing infiltration of CD8+ T cytotoxic lymphocytes, chromatolysis, vacuolization of anterior horn cells and gliosis.

The largest series of myelitis with antiamphiphysin antibodies reported 17 cases in 63 patients with anti-amphiphysin autoimmunity [22]. Presentations were gen-
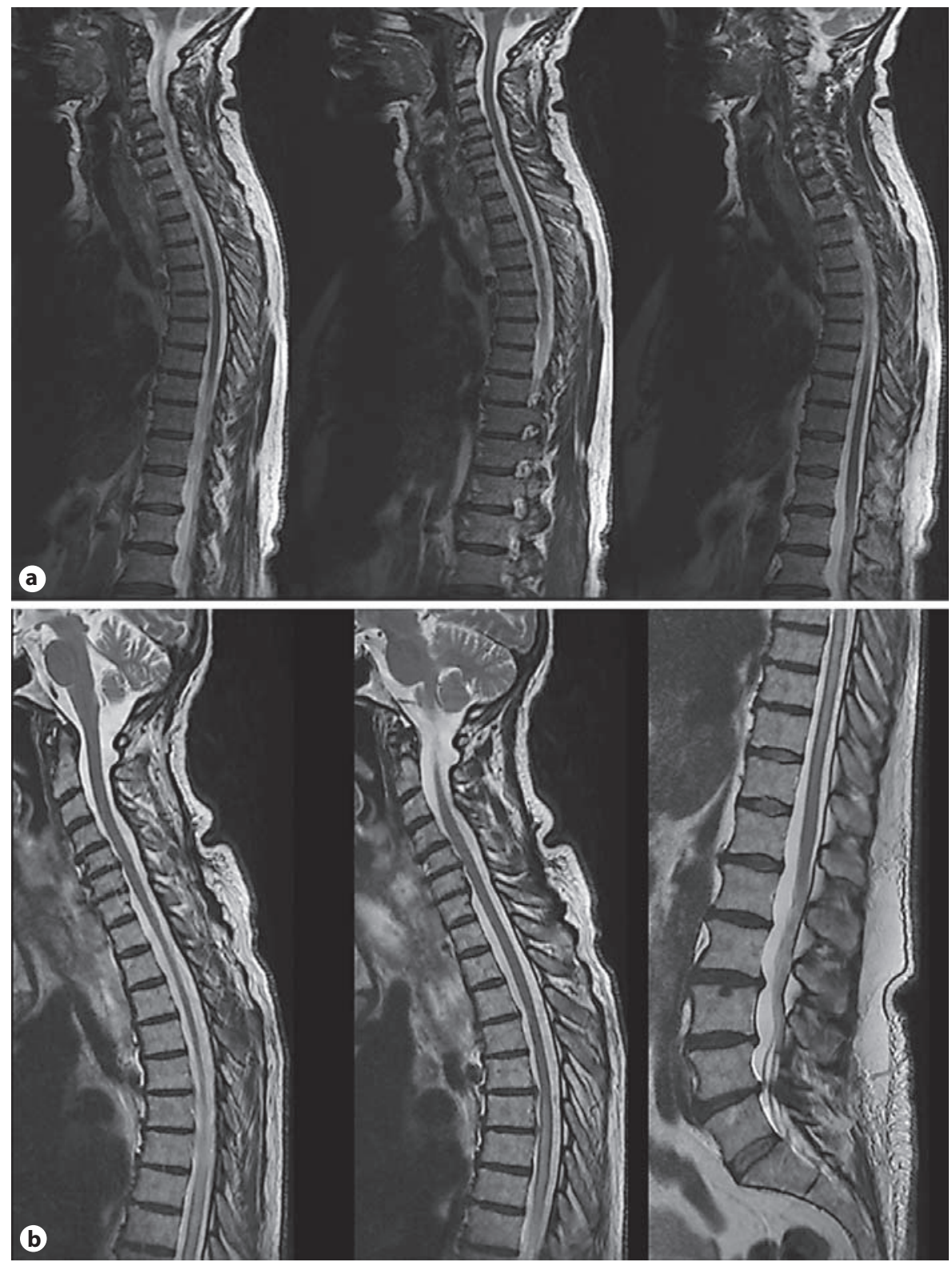

Fig. 1. Medullar MRI a initially normal and b 6 months after disease onset showing extensive transverse myelitis with T2 hypersignal from level Th6 to Th10.

erally subacute with predominantly motor involvement. CSF tests were usually mildly pleocytic with an increased protein level. Seven patients underwent a medullary MRI examination. Five had T2-weighted signal abnormality in the spinal cord and two had normal imaging but clinical symptoms of myelitis. The authors concluded that patients with isolated anti-amphiphysin antibodies are more likely to be women with breast cancer and to have stiff man syndrome or myelopathies compared to patients with anti-amphiphysin antibodies coexisting with autoantibodies [22]. Pittock and Lucchinetti [23] reported that patients presenting with paraneoplastic longitudinally extensive TM are often anti-amphiphysin positive.

The role of anti-amphiphysin antibodies is not fully understood, but injection of 
anti-amphiphysin antibodies causes stiff person syndrome in murine models [24]. Medullary inflammatory reaction could be caused by these antibodies or by neurone hyperactivity leading to exitotoxicity.

This overlap between SLS and paraneoplastic TM with anti-amphiphysin antibodies suggests a common physiopathology of anti-amphiphysin antibodies in stiff man syndrome, SLS and TM. In our case, SLS and TM are probably epiphenomena caused by diffuse spinal involve- ment induced by anti-amphiphysin autoimmunity. SLS and TM are both medullar pathologies, suggesting that anti-amphiphysin antibodies target epitopes that are highly expressed in the spinal cord. These antibodies may induce two physiopathological mechanisms: (1) functional abnormalities, leading to motor hyperexcitability resulting in SLS; and (2) toxic lesions, causing TM. Both mechanisms inducing SLS and TM are associated in our case report.

\section{Acknowledgement}

The authors wish to thank Frances Sheppard of the Clinical Investigation Center of Besançon (INSERM CIT 808) for correcting and improving the English in the manuscript.

\section{Disclosure Statement}

The authors have nothing to disclose.

\section{References}

1 Moersch F, Woltman H: Progressive fluctuating muscular rigidity and spasm ('stiffman' syndrome): report a case and some observations in 13 other cases. Proc Staff Meet Mayo Clin 1956;31:421-427.

-2 Brown P, Marsden CD: The stiff man syndrome and stiff man plus syndromes. J Neurol 1999;246:648-652.

-3 Barker RA, Revesz T, Thom M, Marsden CD, Brown P: Review of 23 patients affected by the stiff man syndrome: clinical subdivision into stiff trunk (man) syndrome, stiff limb syndrome, and progressive encephalomyelitis with rigidity. J Neurol Neurosurg Psychiatry 1998;65:633-640.

-4 Gurol ME, Ertas M, Hanagasi HA, Gürsoy G, Emre M: Stiff leg syndrome: case report. Mov Disord 2001;16:1189-1193.

5 Hattan E, Angle MR, Chalk C: Unexpected benefit of propofol in stiff-person syndrome. Neurology 2008;70:1641-1642.

-6 Saiz A, Graus F, Valldeoriola F, Valls-Solé J, Tolosa E: Stiff-leg syndrome: a focal form of stiff-man syndrome. Ann Neurol 1998;43: 400-403.

7 Cantiniaux S, Azulay JP, Boucraut J, Poujet J, Attarian S: Stiff man syndrome: clinical forms, treatments and clinical course. Rev Neurol 2006;162:832-839.

$\checkmark 8$ Silverman IE: Paraneoplastic stiff limb syndrome. J Neurol Neurosurg Psychiatry 1999; 67:126-127.

\9 Bartsch T, Herzog J, Baron R, Deutschl G: The stiff limb syndrome - a new case and a literature review. J Neurol 2003;250:488490.
$>10$ Kocak E, Abdessalam S, Walker MJ, Nuovo GJ, Kissel JT: Stiff-person syndrome: a rare presentation for breast cancer. Breast J 2004; 10:552-553.

-11 Shiraishi H, Motomura M, Iwanaga H, Tsujino A, Nishiura Y, Shirabe S, Nakamura T, Yoshimura T: Successful treatment in a patient with a focal form of stiff-person syndrome using plasma exchange and intravenous immunoglobulin therapy (in Japanese). Rinsho Shinkeigaku 2002;42:766-770.

12 Weatherby SJ, Woolner P, Clarke CE: Pregnancy in stiff-limb syndrome. Mov Disord 2004; 19:852-854.

13 Coles A, Barker R: A case of stiff limb syndrome responsive to plasma exchange. J Neurol Neurosurg Psychiatry 2001;70:407408.

14 Souza-Lima CF, Ferraz HB, Braz CA, Araüjo AM, Manzano GM: Market improvement in a stiff-limb patient treated with intravenous immunoglobulin. Mov Disord 2000;15:358359.

15 Hajjioui A, Benbouazza K, Faris Mel A, Missaoui A, Hassouni NH: Stiff limb syndrome: a case report. Cases J 2010;3:60.

16 Holmøy T, Horn MA, Vandvik B: A stifflegged man with a bizarre gait. Tidsskr Nor Laegeforen 2007;127:1529-1530.

17 Calvet D, Touzé E, Delegue P, Bertherat J, Zuber M: Syndrome des membres raides associé à une encéphalopathie d'Hashimoto: effet favorable des corticoïdes. Rev Neurol 2002;158:602-604.
18 Schiff D, Dalmau J, Myers DJ: Anti-GAD antibody positive stiff-limb syndrome in multiple myeloma. J Neurooncol 2003;65:173175.

19 Holmøy T: Long-term effect of gabapentin in stiff limb syndrome: a case report. Eur Neurol 2007;58:251-252.

20 Virani S, Tan M, Abraham J: Transverse myelitis: amphiphysin autoimmunity paraneoplastic syndrome in a woman with breast cancer. Clin Adv Hematol Oncol 2009;7: 180-182.

21 Holmøy T, Skorstad G, Roste LS, Scheie D, Alvik K: Stiff person syndrome associated with lower motor neuron disease and infiltration of cytotoxic T cells in the spinal cord. Clin Neurol Neurosurg 2009;111:708-712.

22 Pittock SJ, Lucchinetti CF, Parisi JE, Benarroch EE, Mokri B, Stephan CL, Kim KK, Kilimann MW, Lennon VA: Amphiphysine autoimmunity: paraneoplastic accompaniments. Ann Neurol 2005;58:96-107.

$\checkmark 23$ Pittock SJ, Lucchinetti CF: Inflammatory transverse myelitis: evolving concepts. Curr Opin Neurol 2006;19:362-368.

-24 Geis C, Weishaupt A, Hallermann S, Grünewald B, Wessig C, Wultsch T, Reif A, Byts N, Beck M, Jablonka S, Boettger MK, Üçeyler N, Fouquet W, Gerlach M, Meinck HM, Sirén AL, Sigrist SJ, Toyka KV, Heckmann M, Sommer C: Stiff person syndrome-associated autoantibodies to amphiphysin mediated reduced GABAergic inhibition. Brain 2010; 133:3166-3180. 